\title{
PERAN PERAWAT TERHADAP PELAYANAN KESELAMATAN PASIEN
}

\author{
Ade sulistya lubis/181101121
}

adesulistyalubis@gmail.com

\begin{abstract}
ABSTRAK
Latar belakang: Rumah sakit sebagai sarana pelayanan kesehatan pada dasarnya adalah untuk menyelamatkan pasien, keselamatan pasien merupakan prioritas bagi pelaksanaan lima isu penting tentang keselamatan di rumah sakit, karena masalah keselamatan pasien berkaitan erat dengan kualitas dan citra rumah sakit itu sendiri. Tujuan: Untuk mengetahui bagai man peran perawat dalam melakukan layan kepasa kesalamtan pasien. Metode : Jurnal ini menggunakan metode tersearch dan analisis dari berbagai sumber seperti buku teks, buku referensi jurnal, e-book, dan juga membandingkan beberapa jurnal yang berhubungan dengan peran perawat dalam pelayan keselamatan pasien . Hasil: Dari hasil beberapa pembandingan jurnal mengatakan bahwa peran perawat dalam pelayanan keselamatan pasien sangat berperan penting untuk keselamatan pasien. Kesimpulan: Salah satu tenaga yang berperan dalam usaha peningkatan budaya keselamatan pasien adalah perawat.
\end{abstract}

Kata kunci: Peran perawat, Pelayanan, Keselamatan pasien.

Background: Hospitals as a means of health care are basically to save patients, patient safety is a priority for the implementation of five important issues about safety in hospitals, because patient safety issues are closely related to the quality and image of the hospital itself. Objective: To find out how the role of nurses is in serving the patient's satisfaction. Methods: This journal uses the search method and analysis from various sources such as textbooks, journal reference books, e-books, and also compares journals related to the role of nurses in patient safety services. Results: From the results of several comparison journals said that the role of nurses in patient safety services is very important for patient safety. Conclusion: One of the personnel who play a role in efforts to improve patient safety culture is nurses.

Keywords: Role of nurses, service, patient safety. 
PENDAHULUAN

\section{LATAR BELAKANG}

Rumah sakit adalah sarana pelayanan kesehatan yang dibutuhkan ketika seseorang sakit dan membutuhkan bantuan dengan tujuan untuk menyelamatkan kondisi pasien. Perawat sebagai salah satu tenaga kesehatan yang mempunyai jumlah cukup dominan di rumah sakit yaitu sebesar 50 sampai $60 \%$ dari jumlah tenaga kesehatan yang ada. Pelayanan asuhan keperawatan yang diberikan kepada pasien merupakan pelayanan yang terintegrasi dari pelayanan kesehatan yang lainnya dan memiliki peran yang cukup penting bagi terwujudnya kesehatan dan keselamatan pasien. Perawat adalah pejabat eksekutif kesehatan dengan waktu kerja tertinggi yang memberikan 24 jam pelayanan terus menerus serta harus berkolaborasi dengan tim kesehatan lain dan oleh karena itu lah hal tersebut dapat menyebabkan atau berisiko terjadinya Insiden Keselamatan Pasien1. Selain itu, perawat memiliki peran yang paling dominan dalam mencegah terjadinya kesalahan dalam pengobatan, termasuk pelaporan insiden, mendidik diri sendiri dan orang lain. Sejalan dengan definisi keperawatan ANA
2003 yang menyatakan bahwa keperawatan adalah perlindungan, promosi, dan optimalisasi kesehatan dan kemampuan, pencegahan penyakit dan cedera, pengentasan penderitaan melalui diagnosis dan pengobatan respon manusia, dan advokasi dalam perawatan individu, keluarga, masyarakat, dan populasi. Oleh sebab itu peran perawat dalam mengimplementasikan asuhan keperawatan dan mewujudkan keselamatan pasien di rumah sakit dapat dirumuskan sebagai berikut, perawat harus mematuhi standar layanan dan SOP yang telah ditetapkan, menerapkan prisip etik dalam meberikan asuhan keperawatan, memberikan pendidikan kepada pasien dan keluarga pasien tentang asuhan keperawatan yang sedang dijalankan, selalu bekerjasama dengan tim kesehatan yang lainnya dalam memberikan asuhan keperawatan, menerapkan komunikasi yang baik terhadap sejawat, pasien dan keluarga, selalu proaktif dan peka dalam setiap menyelesaikan kejadian atau insiden yang berkaitan dengan keselamatan pasien, mendokumentasikan segala bentuk kegiatan yang ada hubungannya dengan asuhan keperawatan yang dilakukan kepada pasein. 
Pengobatan dan manajemen dari pasien yang tidak dilakukan dengan hati-hati dan tidak berpotensi terjadinya prosedural Insiden Keselamatan Pasien. Insiden Keselamatan Pasien adalah peristiwa dan kondisi yang tidak disengaja yang mengakibatkan atau berpotensi menyebabkan cedera dapat dicegah pada pasien, Insiden Keselamatan Pasien (IKP) yang terdiri dari Kejadian Tidak Diharapkan (KTD), Kejadian Nyaris Cedera (KNC), Kejadian Tidak Cedera (KTC) dan Kondisi Potensial Cedera (KPC)2. Keselamatan pasien adalah prioritas utama dan harus segera dilaksanakan di rumah sakit karena dapat menyebabkan cedera langsung kepada pasien, juga terkait dengan kualitas dan citra rumah sakit serta standar pelayanan yang harus dipenuhi oleh rumah sakit itu terkait dengan versi 2012 dari standar akreditasi mengacu pada Joint Commission International (JCI). $\mathrm{N}$ dan Walid, S. 2009).

\section{TUJUAN}

Tujuan pembandigan dari beberapa jurnal dan sumber lainnya agar dapat mengetahui peran perawat dalam pelayanan keselamatan pasien.

\section{METODE}

Jurnal ini menggunakan metode tersearch dan analisis dari berbagai sumber seperti buku teks, buku referensi jurnal, e-book, dan juga membandingkan beberapa jurnal yang berhubungan dengan peran perawat dalam pelayan keselamatan pasien . Dari analisi berbagai sumber digunakan Untuk mengetahui bagai mana peran perawat dalam melakukan pelayanan keselamatan pasien. Penulisan jurnal ini dimulai pada tanggal 01 oktober 2019. Pengolahan jurnal dilakukan dengan metode membandingkan beberapa jurnal yang berhubungan peran pearawat dalam melakukan pelayanan keselamatan pasien.

\section{HASIL}

Berdasarkan hasil penelitian dari (Jurnal IKESMA Volume 11 Nomor 1 Maret 2015) terhadap indikator budaya keselamatan yang meliputi kerja sama, komunikasi, kepemimpinan, pelaporan dan respon tidak menghukum terhadap kesalahan 
didapatkan hasil dan pembahasan sebagai berikut :

\section{Kerjasama Kerjasama} merupakan indikator pertama dari budaya keselamatan pasien. Berdasarkan hasil dari penelitian, 73 responden atau sebesar $64,6 \%$ dari sampel yang dipilih (113 perawat) dalam melaksanakan asuhan keperawatan selalu bekerja sama dengan sesama perawat maupun dengan tenaga kesehatan lainnya dengan baik.

\section{Komunikasi}

\section{Berdasarkan}

hasilpenelitian untuk indikator budaya komunikasi didapatkan 61 responden $(54,0 \%)$ dari 113 responden telah melakukan budaya komunikasi.

\section{Kepemimpinan}
Berdasarkan
hasil
penelitian untuk variabel kepemimpinan, dalam hal ini partisipasi pemimpin di semua ruang rawat inap Rumah Sakit X Kabupaten Jember untuk mendukung keselamatan pasien adalah dalam kategori baik, hal ini

didukung oleh hasil penelitian yang sebesar 91,2\% atau sebanyak 103 responden menyatakan hal tersebut.

\section{Pelaporan}

Indikator pelaporan dalam penerapan budaya keselamatan pasien berada dalam kategori cukup. Hal ini didukung oleh hasil penelitian yang menunjukkan bahwa 70 responden $(61,9 \%)$ yang menyatakan hal tersebut.

\section{Respon Tidak Menghukum}

\section{Terhadap Kesalahan}

Seiring dengan hasil indikator pelaporan pada insiden keselamatan pasien, hasil penelitian untuk indikator respon tidak menghukum terhadap kesalahan juga berada dalam kategori cukup. Hal ini ditunjukkan oleh hasil penelitian sebesar 51, 3\% atau sebanyak 58 dari 113 responden menyatakan cukup.

Dari peneliti jurnal (Syarianingsih Syam, nur. Implementasi Budaya Keselamatan Pasien oleh Perawat di Rumah Sakit Ibnu 
Sina Makasar. Kes Mas: Jurnal Fakultas

Kesehatan Masyarakat, Universitas Ahmad Dahlan, Yogyakarta, IndonesiaVolume 11, Issue 2, September 2017, pp. 169 174 ISSN: 1978 - 0575) mengatakan bahwa, Tantangan terbesar yang perlu dilakukan dalam menciptakan budaya keselamatan pasien yang terbuka adalah mendirikan dan mempertahankan budaya positif tentang keselamatan pasien pada organisasi pelayanan kesehatan. Karakteristik budaya positif tentang keselamatan pasien di antaranya adalah persepsi yang diinformasikan tentang pentingnya keselamatan pasien, dan komitmen pemimpin serta tanggung jawab pembuat kebijakan. Scott menyatakan bahwa pengembangan budaya positif keselamatan pasien dapat meningkatkan kinerja karyawan dalam menerapkan program keselamatan pasien. Salah satu tenaga yang berperan dalam usaha peningkatan budaya keselamatan pasien adalah perawat. Perawat melaksanakan tugas 24 jam dalam tujuh hari pelayanan langsung kepada pasien. Pelayanan yang diberikan berupa perawatan langsung dan pemeriksaan keadaan klinis pasien. Selain hal tersebut perawat juga melakukan koordinasi dan integrasi layanan perawatan lintas profesi dan unit.

\section{PEMBAHASAN}

Dari hasil peneliti jurnal (Vena Jaladara, dkk. Hubungan tingkat pengetahuan dan praktik perawat mengenai keselamatan pasien (patient safety) di instalasi gawat darurat rs x semarang. Jurnal kesehatan masyarakat. (e-Journal) Volume 3, Nomor 1, Januari 2015 (ISSN: 2356-3346) http:/lejournals1.undip.ac.id/index.php/jk $\underline{m}$ ). Keselamatan pasien (patient safety) rumah sakit merupakan suatu sistem dimana rumah sakit membuat pelayanan pasien menjadi lebih aman. Sistem tersebut meliputi penilaian risiko, identifikasi dan pengelolaan hal yang berhubungan dengan risiko pasien, pelaporan dan analisis insiden, kemampuan belajar dari insiden dan tindak lanjutnya serta implementasi solusi untuk meminimalisasi timbulnya risiko. Sistem tersebut diharapkan dapat mencegah terjadinya cedera yang disebabkan oleh suatu tindakan yang dilakukan atau tidak melakukan suatu tindakan yang seharusnya dilakukan. 
Berdasarkan dari hasil peneliti (Jurnal IKESMA Volume 11 Nomor 1 Maret 2015) indikator budaya keselamatan yang meliputi pelayanan keselamatan pasien yaitu:

1. Kerjasama Kerjasama merupakan indikator pertama dari budaya keselamatan pasien. Berdasarkan hasil dari penelitian, dalam melaksanakan asuhan keperawatan kepada pasien perawat akan selalu membutuhkan bantuan dari perawat maupun tenaga kesehatan yang lainnya.. banyak profesi selain tenaga perawat dalam melakukan asuhan keperawatan dapat menimbulkan atau berisiko terjadi cidera jika dilakukan tidak dengan komunikasi dan koordinasi yang tepat3, hal itu (cidera) dapat dihindari jika perawat selalu menjaga hubungan baik dengan sesama perawat dan petugas kesehatan lainnya, dan menjaga keharmonisan di lingkungan kerja atau suasana hati untuk mencapai pelayanan kesehatan.

\section{Komunikasi}

\begin{tabular}{|c|c|c|}
\hline \multicolumn{2}{|c|}{ Komunikasi } & sangatlah \\
\hline penting & dalam & setiap \\
\hline \multicolumn{3}{|c|}{ melaksanakan tugas dalam hal ini } \\
\hline adalah & melaksanaka & asuhi \\
\hline keperay & pada & \\
\hline
\end{tabular}

Komunikasi yang baik dan benar perlu dilakukan untuk mengkoordinasikan asuhan keperawatan yang melibatkan banyak profesi selain profesi perawat. Komuniasi dalam praktek keperawatan merupakan elemen penting bagi perawat dalam melaksanakan asuhan keperawatan untuk mendapatkan hasil yang optimal. Perawat memiliki peran yang paling dominan dalam mencegah terjadinya kesalahan dalam pengobatan, termasuk pelaporan insiden, mendidik diri sendiri dan perawat lain tentang penting komunikasi, memberikan rekomendasi untuk perubahan prosedur dan kebijakan serta keterlibatan dalam melakukan identifikasi permasalahan.

\section{Kepemimpinan}

Pemimpin harus memiliki komitmen yang kuat terhadap keselamatan pasien, sehingga 
keselamatan pasien menjadi hal yang utama dalam memberikan pelayanan keperawatan. Pemimpin harus mampu menjadi agen perubahan bagi anak buahnya dengan melaksanakan program keselamatan pasien. Pimpinan mendorong dan menjamin implementasi program keselamatan pasien secara terintegrasi dalam organisasi melalui penerapan "Tujuh Langkah Menuju Keselamatan Pasien Rumah Sakit". Pemimpin harus membangun komitmen dan fokus yang kuat dan jelas guna mendukung staff untuk menjalankan program keselamatan pasien secara berkesinambungan, memprioritaskan atau mengintegrasikan program keselamatan pasien dalam setiap rapat dengan para pengambil keputusan, mengagendakan pelatihan tentang keselamatan pasien bagi semua staf secara berkala dan berkesinambungan. Pimpinan menjamin berlangsungnya program proaktif untuk identifikasi risiko keselamatan pasien dan program menekan atau mengurangi Kejadian Tidak Diharapkan. Pimpinan mendorong dan menumbuhkan komunikasi dan koordinasi antar unit dan individu berkaitan dengan pengambilan keputusan tentang keselamatan pasien.

4. Pelaporan

Indikator pelaporan dalam penerapan budaya keselamatan pasien berada dalam kategori cukup. Perawat diharuskan melaporkan kejadian kesalahan yang tidak disengaja dan kondisi yang mengakibatkan atau berpotensi mengakibatkan cedera yang dapat dicegah pada pasien, yang terdiri dari kejadian tidak diharapkan, kejadian nyaris cedera, kejadian tidak cedera dan kejadian potensial cedera. Melaporkan sebuah kejadian atau insiden keselamatan pasien masih jarang dilakukan atau pun bahkan jika ada pelaporan tentang insiden atau kejadian keselamatan pasien belum ada pelaporan secara resmi. Hal ini disebabkan para perawat 
takut untuk melaporkan insiden yang terjadi pada pasien karena kesalahan yang dilakukannya. Perawat merasa takut akan hukuman dari penyelia atas kesalahan yang telah ia lakukan saat melakukan asuhan keperawatan.

5. Respon Tidak Menghukum Terhadap Kesalahan.

Indikator respon tidak menghukum terhadap kesalahan ini menunjukkan bahwa dimasa yang akan datang pelaporan terhadap insiden keselamatan pasien tidak semata-mata hanya berupa pelaporan insiden keselamatan, namun pelaporan tersebut hendaknya ditindaklanjuti guna memperbaiki kesalahan dan mencari akar permasalahan, tidak untuk menghukum perawat yang melakukan kesalahan atau berpengaruh terhadap penilainan kinerjanya. Ketika kesalahan dilaporkan, maka cukup melaporkan masalah sendiri dilaporkan menemukan jalan keluar tidak menunjukkan siapa pelaku harus dihukum. Belajar dari insiden keselamatan pasien hanya akan berhasil jika setiap permasalahan tidak dilihat sebagai kesalahan individu tetapi harus diperhatikan dengan pendekatan sistem dan pemahaman faktor manusia. Sebagaimana diatur dalam Peraturan Menteri Kesehatan Republik Indonesia nomer 755/Menkes/Per/IV/2011 tentang pelaksanaan komite medis di rumah sakit bahwa audit medis dilakukan dengan memprioritaskan semua staf untuk menghilangkan blaming (menyalahkan), naming (menyebut atau mencari siapa yang salah), dan shaming (mempermalukan atau mengakui kesalahan).

Standar pelayanan kesehatan di Indonesia masih kurang optimal jika dibandingkan dengan negara maju seperti Amerika dan Inggris. Hughes menyatakan bahwa langkah awal untuk memperbaiki pelayanan yang berkualitas adalah keselamatan, sedangkan kunci dari pelayanan yang bermutu dan aman adalah membangun budaya keselamatan pasien. Di Indonesia sendiri upaya untuk 
menurunkan angka KTD dan KNC adalah dengan mencanangkan "Gerakan Keselamatan Pasien di Rumah Sakit". Gerakan ini baru dicanangkan pada tahun 2005 silam, namun hingga kini penerapannya belum komprehensif.

Di rumah sakit salah satu tenaga yang berperan dalam meningkatkan keselamatan pasien adalah perawat. Keselamatan pasien bagi perawat tidak hanya merupakan pedoman tentang apa yang seharusnya dilakukan, namun keselamatan pasien merupakan komitmen yang tertuang dalam kode etik perawat dalam memberikan pelayanan yang aman, sesuai kompetensi, dan berlandaskan kode etik bagi pasien. Luasnya peran perawat memungkinkannya untuk menemukan dan mengalami risiko kesalahan pelayanan. Temuan kesalahan pelayanan hanya akan dilaporkan jika si perawat merasa aman dan mendapat pelakuan terbuka dan adil.

\section{KESIMPULAN}

Dari beberapa hasil penelitian jurnal mengatakan bahwa, Salah satu tenaga yang berperan dalam usaha peningkatan budaya keselamatan pasien adalah perawat. Peran perawat dalam mengimplementasikan asuhan keperawatan dan mewujudkan keselamatan pasien di rumah sakit dapat dirumuskan sebagai berikut, perawat harus mematuhi standar layanan dan SOP yang telah ditetapkan, menerapkan prisip etik dalam meberikan asuhan keperawatan, memberikan pendidikan kepada pasien dan keluarga pasien tentang asuhan keperawatan yang sedang dijalankan, oleh karena itu, Peran perawat terhadap pelayanan keselamatan pasien sangat berperan penting untuk keselamatan pasien.

\section{SARAN}

Pelayanan keselamatan pasien merupakan salah satu tindakan perawat dirumah sakit yang harus lebih di tingkatkan. Perawat berperan penting atas keselamatan pasien di rumah salin. Oleh karena itu, setiap rumah sakit di sarankan menerapkan sistem keselamatan pasien dalam rangka meningkatkan pelayanan yang lebih bermutu dan aman serta menjalankan peraturan perundang-undangan yang mewajibkan untuk itu. Agar seluruh komponen sarana pelayanan kesehatan 
bekerja sama dalam upaya mewujudkan patient safety karena upaya keselamatan pasien hanya bisa dicapai dengan baik dengan kerjasama semua pihak.

\section{REFERENSI}

Asmuji; Manajemen Keperawatan (Konsep dan Aplikasi), Jogjakarta 2014.

Kusumapraja, R. 2011. Perencanaan Kebutuhan Tenaga Perawat di RS. MakalahManajemen Keperawatan. RSU Persahabatan. Jakarta.

Komite Keselamatan Pasien Rumah Sakit (KKP-RS). Laporan Insiden Keselamatan Pasien. Jakarta: Kementerian Kesehatan Republik Indonesia; 2011.

Komite Keselamapatan Pasien Rumah Sakit. Laporan Insiden Keselamatan Pasien Periode : September-Desember 2010. 2010 (Online)(http://www.inapatsafety persi.or.id/?show=data/triwulan3 2010/lap_ikp32 010) diakses pada tanggal 27 September 2014 pukul 19.37 WIB
Menteri Kesehatan Indonesia. Peraturan Menteri Kesehatan Indonesia Nomor1691/MENKES/PER/VIII /2011 Tentang Keselamatan Pasien Rumah Sakit. Departemen Kesehatan Republik Indonesia. 2011

Nursalam; Manajemen Keperawatan (Aplikasi dalam Praktik Keperawatan Profesional) edisi 4, Jakarta 2014.

Notoatmodjo, Soekidjo. Promosi Kesehatan dan Perilaku Kesehatan Edisi Revisi 2012. Rineka Cipta. Jakarta. 2012

Ramsey, G, Nurse, medical errors, and culture of blame. Proquest HealthManagement. 2 (25), 2527.[serialonline].http://proquest. umi.com/pq dweb/. (12 April 2013).

Vena Jaladara, dkk. Hubungan tingkat pengetahuan dan praktik perawat mengenai keselamatan pasien (patient safety) di instalasi gawat darurat rs $\mathrm{X}$ semarang.Jurnal kesehatan masyarakat (eJournal) Volume 3, Nomor 1, 
Januari 2015 (ISSN: 2356-3346)

http://ejournals1.undip.ac.id/ind ex.php/jkm

Syarianingsih Syam, nur. Implementasi Budaya Keselamatan Pasien oleh Perawat di Rumah Sakit Ibnu Sina Makasar. Kes Mas: Jurnal Fakultas Kesehatan Masyarakat, Universitas Ahmad Dahlan, Yogyakarta, IndonesiaVolume 11, Issue 2, September 2017, pp. 169 174 ISSN: 1978 - 0575

Sri yulia,dkk. Peran perawat terhadap pelayanan keselamatan pasien. Jurnal Indonesia, vol 15, no 3, November hal 2012; hal 185192.

Simamora, R. H. “ Buku Aajar keselamatan pasien melalui timbang terima pasien berbasis komunikasi efektif:

SBAR.."(2018).

Tri Herawat, Yennike. Budaya Keselamatan Pasien Di Ruang Rawat Inap Rumah Sakit X Kabupaten Jember, Jurnal IKESMA Volume 11 Nomor 1 Maret 2015.
Potter, P. A., \& Perry, A. G., (2010). Fundamental of nursing. Buku 1, edisi 7. Jakarta : Salemba Medika.

Potter, P. A., \& Perry, A. G., (2013). Fundamentals of nursing. $\left(^{\text {th }}\right.$ ed). Elsevier. 